\title{
TERNARY Bi-Cu-Ni ALLOYS - THERMODYNAMICS, CHARACTERIZATION, MECHANICAL AND ELECTRICAL PROPERTIES
}

\author{
Branislav Marković ${ }^{\prime *}$, Dragan Manasijević ${ }^{2}$, Nadežda Talijan ${ }^{3}$, Miroslav \\ Sokic ${ }^{1}$, Nada Štrbac ${ }^{2}$, Aleksandra Patarić ${ }^{1}$, Mladen Bugarčić ${ }^{l}$ \\ ${ }^{1}$ Institute for Technology of Nuclear and Other Mineral Raw Materials, 86 \\ Franchet d'Esperey Street, 11000 Belgrade, Serbia \\ ${ }^{2}$ University of Belgrade, Technical Faculty, Vojske Jugoslavije 12, \\ 19210 Bor, Serbia \\ ${ }^{3}$ Institute of Chemistry, Technology and Metallurgy, Njegoševa 12, \\ 11000 Belgrade, Serbia
}

Received 05.09.2017

Accepted 19.09.2017

\begin{abstract}
The Bi-Cu-Ni ternary system belongs to the group of potential $\mathrm{Cu}-\mathrm{Ni}$-based advanced lead-free solder materials for high temperature application. The paper shows results of the thermodynamic calculations using general solution model along the line with the molar ratio of $\mathrm{Cu}: \mathrm{Ni}=1: 1$. The experimental part shows thermal, structural, electrical and mechanical properties based on differential scanning calorimetry (DSC), scanning electron microscopy with energy dispersive spectrometry (SEM-EDS), electroconductivity and hardness measurements of the alloys selected in the section from bismuth corner with molar ratio $\mathrm{Cu}: \mathrm{Ni}=1: 1, \mathrm{Cu}: \mathrm{Ni}=3: 1$, and $\mathrm{Cu}: \mathrm{Ni}=1: 3$.
\end{abstract}

Keywords: $\mathrm{Bi}-\mathrm{Cu}-\mathrm{Ni}$ ternary alloys; lead-free solders; thermodynamic calculations; characterization.

\section{Introduction}

The high toxicity of lead and damaging effects on the environment result in the prohibited use of the electronic materials (RoHS Directive from 1 July 2006 in the EU). Therefore, great effort has been made to the development of new $\mathrm{Pb}$-free soldering and brazing materials. [1-7]. The Bi-Cu-Ni ternary system is a very significant because its alloys belong to the group of potential $\mathrm{Cu}$-Ni-based advanced lead-free solder materials for high temperature application. This system represents environmental friendly

${ }^{*}$ Corresponding author: Branislav Marković, b.markovic@itnms.ac.rs 
alternatives to Sn-based solders which has been examined recently in the frame of COST MP0602 "HISOLD" project [8] and has been described in the literature [9, 10]. Gao et al. [9] investigated phase equilibria of the $\mathrm{Bi}-\mathrm{Cu}-\mathrm{Ni}$ system at 300, 400, and $500{ }^{\circ} \mathrm{C}$ using metallography and electron probe microanalysis on equilibrated alloys and diffusion couples, while Marković et al. [10] performed thermodynamic modeling of the $\mathrm{Bi}-\mathrm{Cu}-\mathrm{Ni}$ system using CALPHAD technique. The liquidus projection of investigated $\mathrm{Bi}-\mathrm{Cu}-\mathrm{Ni}$ system is given in Fig.1, according to the literature [10].

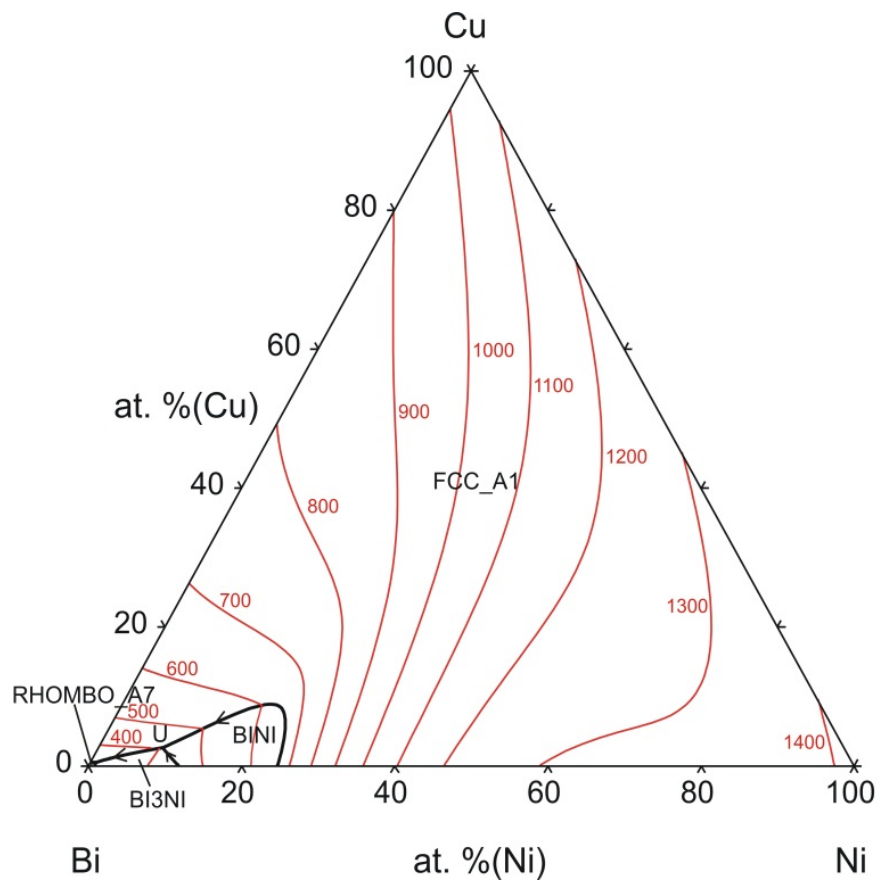

Fig.1. Liquidus projection of investigated Bi-Cu-Ni system [10].

Having in mind the importance the $\mathrm{Bi}-\mathrm{Cu}-\mathrm{Ni}$ alloys data for understanding the processes occurring during soldering and operations with the soldered devices, results of the thermodynamic analysis and characterization of mentioned ternary alloys are presented in this paper. Also, the mechanical and electrical properties in the given system are measured and discussed.

\section{Experimental}

The composition of selected $\mathrm{Bi}-\mathrm{Cu}-\mathrm{Ni}$ alloys, from the bismuth corner section, with molar ratio $\mathrm{Cu}: \mathrm{Ni}=1: 1$, are given in Table 1 . These samples were experimentally investigated using differential scanning calorimetry (DSC) and scanning electron microscopy with energy dispersive spectrometry (SEM-EDX), while mechanical and electrical investigations were performed along all three sections from the bismuth corner, with molar ratio $\mathrm{Cu}: \mathrm{Ni}=1: 1, \mathrm{Cu}: \mathrm{Ni}=3: 1$ and $\mathrm{Cu}: \mathrm{Ni}=1: 3$. 
Table 1. Composition of investigated Bi-Cu-Ni samples.

\begin{tabular}{lllll}
\hline \multirow{2}{*}{ Section } & \multirow{2}{*}{ Sample } & \multicolumn{3}{c}{ Molar content } \\
& & $\mathrm{xBi}$ & $\mathrm{xCu}$ & $\mathrm{xNi}$ \\
\hline \multirow{3}{*}{$\mathrm{Cu}: \mathrm{Ni}=1: 1$} & $\mathrm{D} 1$ & 0.100 & 0.450 & 0.450 \\
& $\mathrm{~J} 1$ & 0.400 & 0.300 & 0.300 \\
& 0.900 & 0.050 & 0.050 \\
\hline
\end{tabular}

The samples were prepared by induction melting under argon atmosphere, with purity of metal components higher than $99.99 \%$. The alloy samples were homogenized at $800{ }^{\circ} \mathrm{C}$ for several hours under an argon atmosphere and then slowly cooled to the room temperature. The total mass losses of the prepared ingots were less than 1 mass $\%$.

The DSC measurements were performed on an SDT Q600 (TA instruments) device. Alumina crucibles were used and measurements were performed under flowing argon atmosphere and a heating rate of $5^{\circ} \mathrm{C} / \mathrm{min}$.

SEM analysis was done using JEOL JSM 6460 apparatus with energy dispersive spectrometry, EDS (Oxford Instruments).

The electrical conductivity of investigated samples was measured using the standard apparatus SIGMATEST 2.069 (Foerster) eddy current instrument for measurements of electrical conductivity of non-ferromagnetic metals, based on the complex impedance of the measuring probe with a diameter of $8 \mathrm{~mm}$. The hardness measurements were done using standard procedure according to Vickers.

The samples were prepared without etching agent application for structure development.

\section{Theoretical Fundamentals}

The basic equations of general solution model $[11,12]$ are given as follows:

$G^{E}=x_{1} x_{2}\left(A^{o}{ }_{12}+A_{12}^{1}\left(x_{1}-x_{2}\right)+A_{12}^{2}\left(x_{1}-x_{2}\right)^{2}\right)+x_{2} x_{3}\left(A^{o}{ }_{23}+A^{1}{ }_{23}\left(x_{2}-x_{3}\right)+A^{2}{ }_{23}\left(x_{2-}\right.\right.$

$\left.\left.x_{3}\right)^{2}\right)+x_{3} x_{1}\left(A^{o}{ }_{31}+A^{1}{ }_{31}\left(x_{3}-x_{1}\right)+A^{2}{ }_{31}\left(x_{3}-x_{1}\right)^{2}\right)+$

where $\mathrm{A}_{\mathrm{ij}}^{\mathrm{o}}, \mathrm{A}_{\mathrm{ij}} \mathrm{A}_{\mathrm{ij}}{ }_{\mathrm{ij}}$ are parameters for binary system "ij" independent of composition, only relying on temperature, which have been used in the regular type equation:

$$
G^{E}{ }_{i j}=X_{i} X_{j}\left(A^{o}{ }_{i j}+A_{i j}^{1}\left(X_{i}-X_{j}\right)+A_{i j}^{2}\left(X_{i}-X_{j}\right)^{2}+\ldots+A_{i j}^{n}\left(X_{i}-X_{j}\right)^{2}\right)
$$

where $X_{i}$ and $X_{j}$ indicate the mole fraction of component " $i$ " and " $\mathrm{j}$ " in "ij" binary system. The function $\mathrm{f}$ is the ternary interaction coefficient expressed by $[11,12]$

$$
f=\left(2 \xi_{12}-1\right)\left\{A^{2}{ }_{12}\left(\left(2 \xi_{12}-1\right) x_{3}+2\left(x_{1}-x_{2}\right)\right)+A_{12}^{1}\right\}+\left(2 \xi_{23}-1\right)\left\{A ^ { 2 } { } _ { 2 3 } \left(\left(2 \xi_{23}-1\right) x_{1}+\right.\right.
$$

$\left.\left.2\left(x_{2}-x_{3}\right)\right)+A^{1}{ }_{23}\right\}+\left(2 \xi_{31}-1\right)\left\{A^{2}{ }_{31}\left(\left(2 \xi_{31}-1\right) x_{2}+2\left(x_{3}-x_{1}\right)\right)+A^{1}{ }_{31}\right\}$

where $\xi_{\mathrm{ij}}$ are the similarity coefficients defined by $\eta_{\mathrm{i}}$ called the deviation sum of squares: 
$\xi_{i j}=\eta_{i} /\left(\eta_{i}+\eta_{j}\right)$

where

$$
\begin{aligned}
& \eta_{I}=\int_{X_{i}=0}^{X_{i}=1}\left(G_{12}^{E}-G_{13}^{E}\right)^{2} d X_{1} \\
& \eta_{I I}=\int_{X_{i}=0}^{X_{i}=1}\left(G_{21}^{E}-G_{23}^{E}\right)^{2} d X_{2} \\
& \eta_{I I I}=\int_{X_{i}=0}^{X_{i}=1}\left(G_{31}^{E}-G_{32}^{E}\right)^{2} d X_{3}
\end{aligned}
$$

and

$$
\begin{aligned}
& X_{1(12)}=x_{1}+x_{3} \xi_{12} \\
& X_{2(23)}=x_{2}+x_{1} \xi_{23} \\
& X_{3(31)}=x_{3}+x_{2} \xi_{31}
\end{aligned}
$$

In all given equations, $\mathrm{G}^{\mathrm{E}}$ and $\mathrm{G}_{\mathrm{ij}}$ correspond to the integral molar excess Gibbs energies for ternary and binary systems, respectively, while $\mathrm{x}_{1}, \mathrm{x}_{2}, \mathrm{x}_{3}$ correspond to the mole fraction of components in the investigated ternary system $[11,12]$.

\section{Results and Discussion}

The thermodynamic calculation in the ternary Bi-Cu-Ni system was performed along the line of a constant $\mathrm{Cu}$ :Ni molar ratio of 1:1 at a temperature of $1273 \mathrm{~K}$.

Starting data for the calculation according to general solution model $[11,12]$ were taken from COST 531 Thermodynamic Database [13], including thermodynamic data for the binary systems $\mathrm{Bi}-\mathrm{Cu}, \mathrm{Cu}-\mathrm{Ni}$, and $\mathrm{Bi}-\mathrm{Ni}$. The Redlich-Kister parameters (in $\mathrm{J} / \mathrm{mol}$ ) for the liquid phase of the constitutional binaries in the investigated $\mathrm{Bi}-\mathrm{Cu}-\mathrm{Ni}$ system are presented in Table 2. 
Table 2. Redlich-Kister parameters for the liquidus phase of constitutional binaries.

\begin{tabular}{lccc}
\hline System & Bi-Cu & Cu-Ni & Bi-Ni \\
\hline$A^{\mathrm{o}}{ }_{\mathrm{ij}}(\mathrm{T})$ & $23844.75-9.84341 * \mathrm{~T}$ & $12048.61+1.29893^{* \mathrm{~T}}$ & $-6440+13.288^{* \mathrm{~T}}$ \\
$A^{1}{ }_{\mathrm{ij}}(\mathrm{T})$ & $-1260.32-1.19289 * \mathrm{~T}$ & $-1861.61+0.94201 * \mathrm{~T}$ & $-11315-1.457 * \mathrm{~T}$ \\
$A^{2}{ }_{\mathrm{ij}}(\mathrm{T})$ & 0 & 0 & 0 \\
\hline
\end{tabular}

Based on the given starting data, similarity coefficients were determined according to the procedure of general solution model $[11,12]$ and their values are as follows: $\xi_{\mathrm{Bi}-\mathrm{Cu}}=0.854, \xi_{\mathrm{Cu}-\mathrm{Ni}}=0.144$ and $\xi_{\mathrm{Ni}-\mathrm{Bi}}=0.505$.

The further calculation was carried out for the alloys in a selected section of $\mathrm{Bi}-\mathrm{Cu}-\mathrm{Ni}$ ternary system at an investigated temperature of $1273 \mathrm{~K}$, according to the fundamentals of general solution model $[11,12]$, given by Eqs. (1-6). The results of thermodynamic predicting, including integral molar Gibbs excess energy and calculated bismuth activities at the temperature of $1273 \mathrm{~K}$, are given in Table 3 and Fig. 2, respectively.

Table 3. Integral molar Gibbs excess energies, $G^{E}$ at investigated temperature of $1273 \mathrm{~K}$

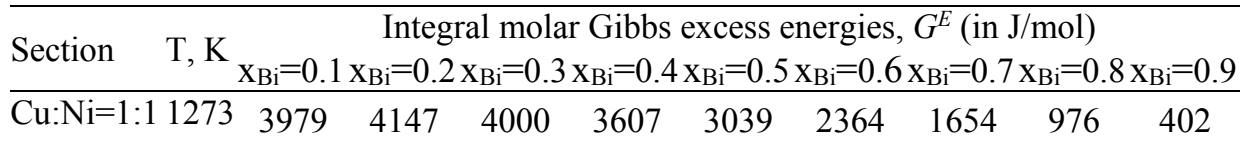

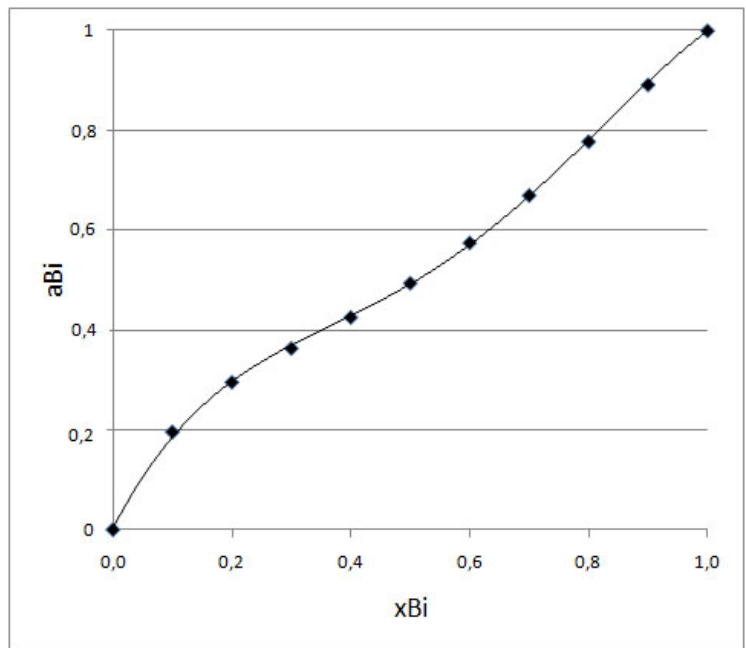

Fig.2. Dependence of $a_{B i}$, calculated by GSM, on bismuth content at $1273 \mathrm{~K}$. 
The values of integral molar Gibbs excess energies are varying in the interval from $+4 \mathrm{~kJ} / \mathrm{mol}$ to $+0.4 \mathrm{~kJ} / \mathrm{mol}$, where positive values are typical for the section with $\mathrm{Cu}: \mathrm{Ni}=1: 1$ in the whole concentration range (Table 3 ). Also, it may be noticed that a deviation from Raoult law is presented in the investigated section, showing a change from strongly positive to slightly positive behavior at bismuth content near to the equiatomic composition.

The results of the thermal analysis, performed using DSC and measured during the heating stage, are presented in Table 4 and Fig. 3 for the sample J1.

Table 4. The results of DSC measurements.

\begin{tabular}{lll}
\hline \multirow{2}{*}{$\begin{array}{l}\text { Sample } \\
\text { (composition in at.\%) }\end{array}$} & \multicolumn{2}{c}{ Temperature, ${ }^{\circ} \mathrm{C}$} \\
& transitions & Liquidus \\
\hline A1 - Bi10Cu45Ni45 & 349,620 & 1243 \\
D1 - Bi40Cu10Ni10 & $410,505,620$ & 1005 \\
J1 - Bi90Cu5Ni5 [Ref. 10] & 270,427 & 544 \\
\hline
\end{tabular}

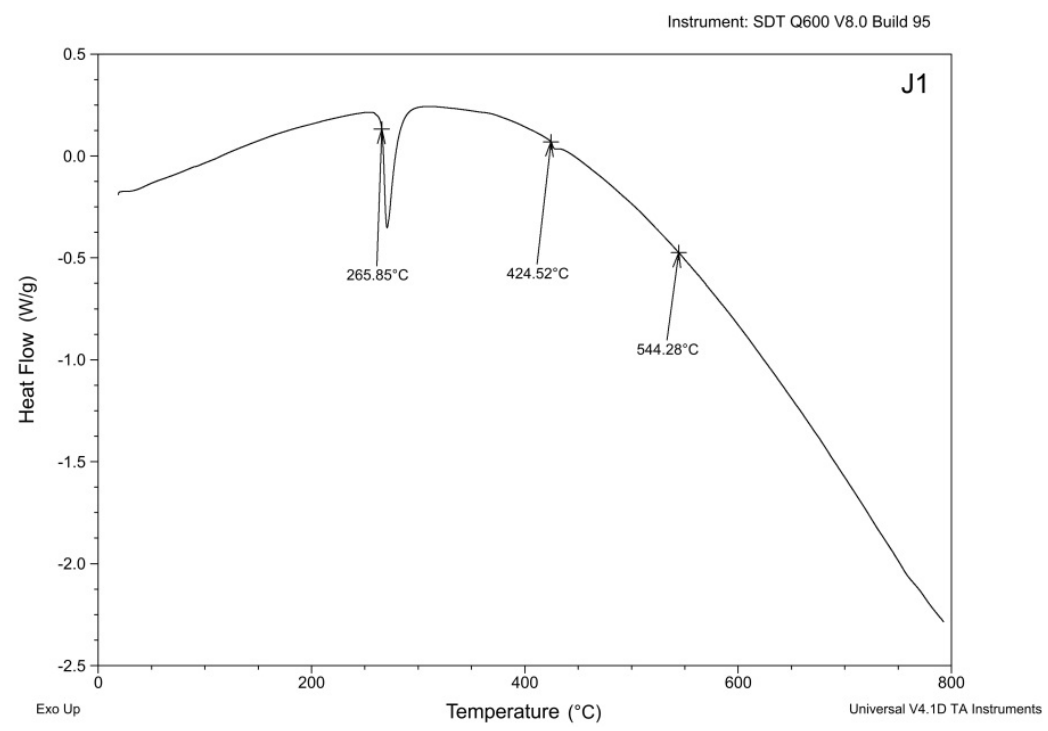

Fig. 3. Characteristic DSC curve for the sample J1.

Obtained endothermic peaks for investigated samples in $\mathrm{Bi}-\mathrm{Cu}-\mathrm{Ni}$ system indicate the characteristic transition and liquidus temperatures.

The results of SEM-EDS are presented in Fig.4 and Table 5. 

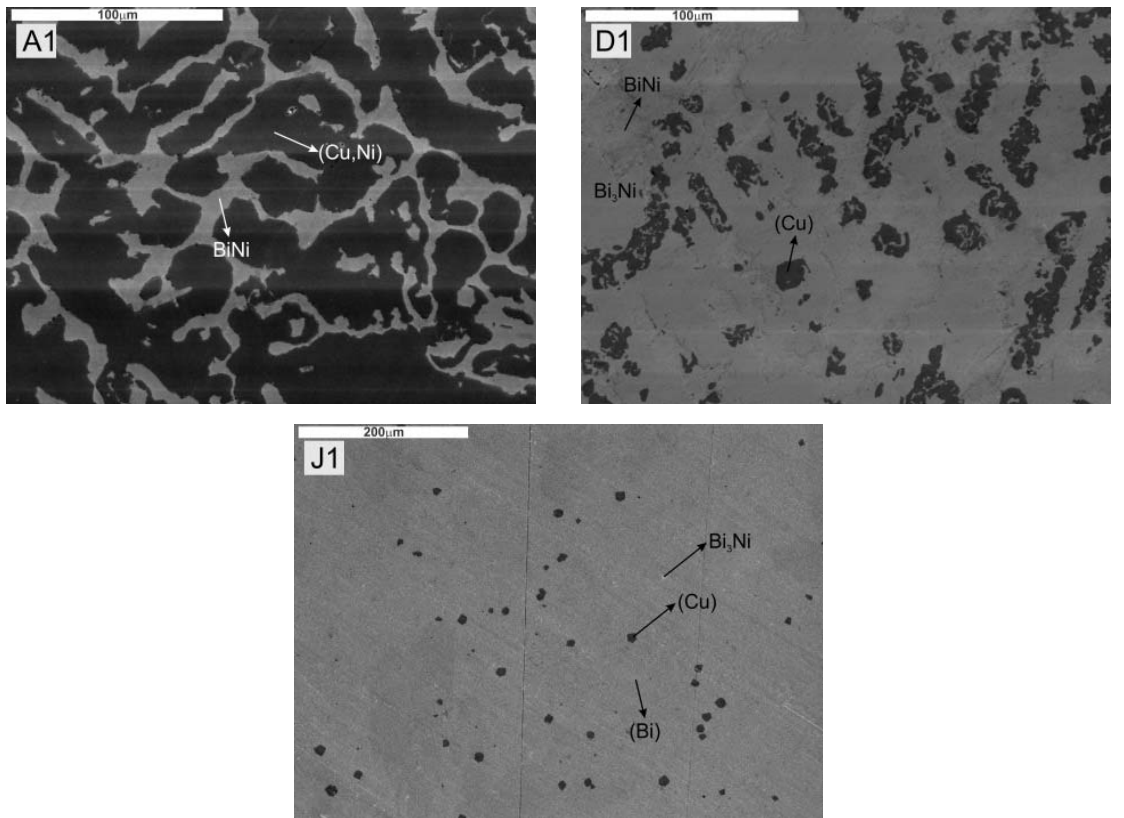

Fig.4. Characteristics SEM microphotographs of investigated samples [14].

Table 5. The results of EDS analysis.

\begin{tabular}{lll}
\hline Sample & \multicolumn{3}{c}{ Present phase } \\
& Light & Dark \\
\hline A1 & BINI & FCC_A1 \\
D1 & BINI, Bi3NI & FCC_A1 \\
J1 & BI3NI, RHOMBO_A7 & FCC_A1 \\
\hline
\end{tabular}

According to its crystallographic data, given in the literature [15], the $\mathrm{Bi}-\mathrm{Cu}-\mathrm{Ni}$ system consists of five phases: liquid, RHOMBO_A7 (Bi), FCC_A1 (Cu, Ni), BiNi and $\mathrm{Bi}_{3} \mathrm{Ni}$. Structural analysis done using SEM-EDS method confirmed the existence of all given phases in this ternary system. So, dark phase in all investigated samples is related to $\mathrm{Cu}-\mathrm{Ni}$-based $\mathrm{FCC}$ A1 phase, while the light phase is related to Bi-Ni-based phases BINI, BI3NI and Bi-based RHOMBO_A7 phase.

The hardness measurements in the $\mathrm{Bi}-\mathrm{Cu}-\mathrm{Ni}$ system are done on the samples from the three selected sections from the bismuth corner, with $\mathrm{Cu}$ :Ni molar ratio of $1: 1$, $3: 1$ and 1:3. The results of the hardness measurements, according to Vickers are given in Table 6. 
Table 6. The results of hardness measurements.

\begin{tabular}{|c|c|c|c|}
\hline \multicolumn{3}{|c|}{ Mole fraction of components } & \multirow{2}{*}{ HV5 } \\
\hline $\mathrm{XBi}$ & $\mathrm{XCu}$ & $\mathrm{XNi}$ & \\
\hline 0.1 & 0.45 & 0.45 & 142.6 \\
\hline 0.2 & 0.4 & 0.4 & 126.3 \\
\hline 0.3 & 0.35 & 0.35 & 108.8 \\
\hline 0.4 & 0.3 & 0.3 & 85.2 \\
\hline 0.5 & 0.25 & 0.25 & 71.6 \\
\hline 0.6 & 0.2 & 0.2 & 59.7 \\
\hline 0.7 & 0.15 & 0.15 & 35.6 \\
\hline 0.8 & 0.1 & 0.1 & 20.7 \\
\hline 0.9 & 0.05 & 0.05 & 15.3 \\
\hline 0.1 & 0.675 & 0.225 & 99 \\
\hline 0.2 & 0.6 & 0.2 & 70.4 \\
\hline 0.3 & 0.525 & 0.175 & 43.3 \\
\hline 0.4 & 0.45 & 0.15 & 40.9 \\
\hline 0.5 & 0.375 & 0.125 & 30.8 \\
\hline 0.6 & 0.3 & 0.1 & 28.6 \\
\hline 0.7 & 0.225 & 0.075 & 23.4 \\
\hline 0.8 & 0.15 & 0.05 & 15.5 \\
\hline 0.9 & 0.075 & 0.025 & 13.7 \\
\hline 0.1 & 0.225 & 0.675 & 159.6 \\
\hline 0.2 & 0.2 & 0.6 & 146 \\
\hline 0.3 & 0.175 & 0.525 & 131 \\
\hline 0.4 & 0.15 & 0.45 & 111.8 \\
\hline 0.5 & 0.125 & 0.375 & 88.9 \\
\hline 0.6 & 0.1 & 0.3 & 68.8 \\
\hline 0.7 & 0.075 & 0.225 & 49 \\
\hline 0.8 & 0.05 & 0.15 & 27.6 \\
\hline 0.9 & 0.025 & 0.075 & 21.2 \\
\hline
\end{tabular}

The change of hardness depending on the bismuth composition is shown in Fig.5. With the increasing content of $\mathrm{Bi}$ the value of hardness decreases. 

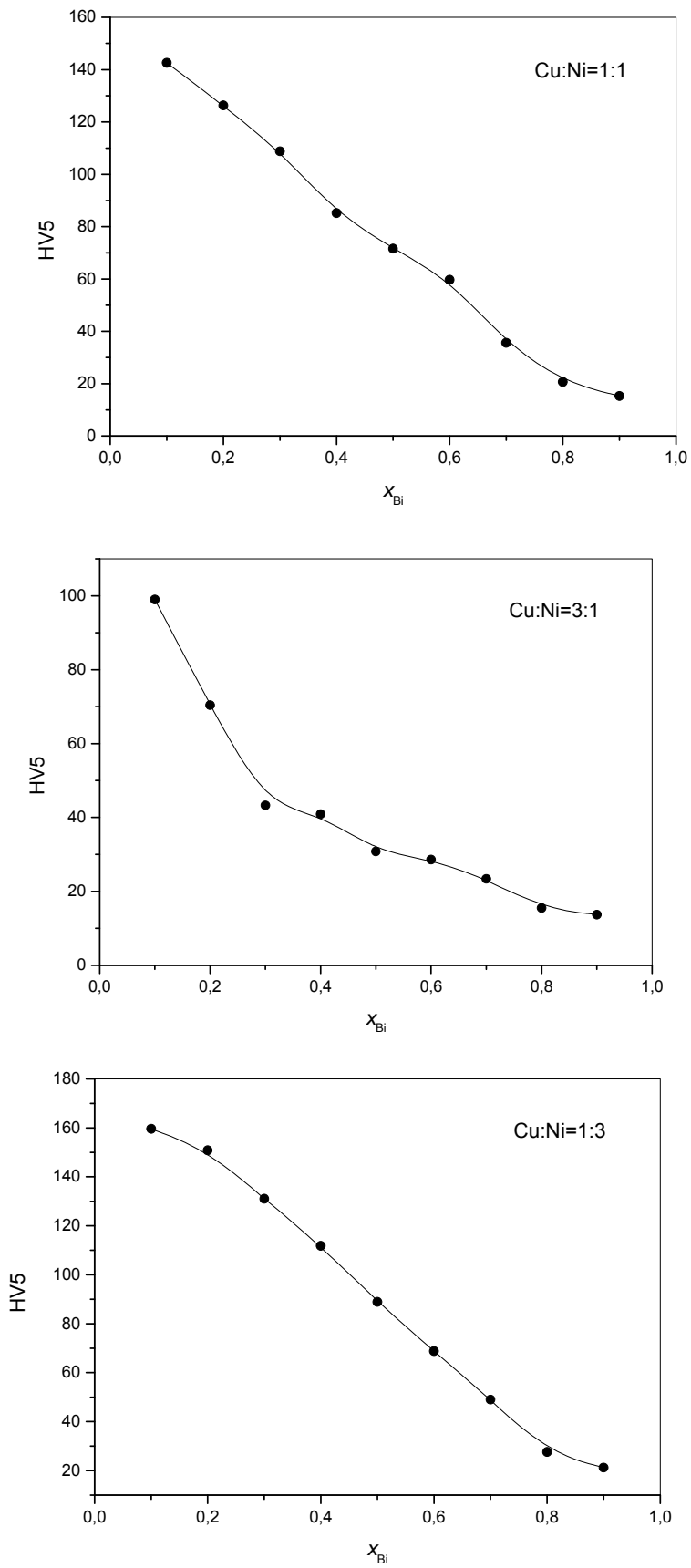

Fig. 5. The hardness change of the Bi composition with different Cu:Ni ratios. 
Based on these results, iso-lines of hardness in the ternary Bi-Cu-Ni system was constructed and shown in Fig.6.

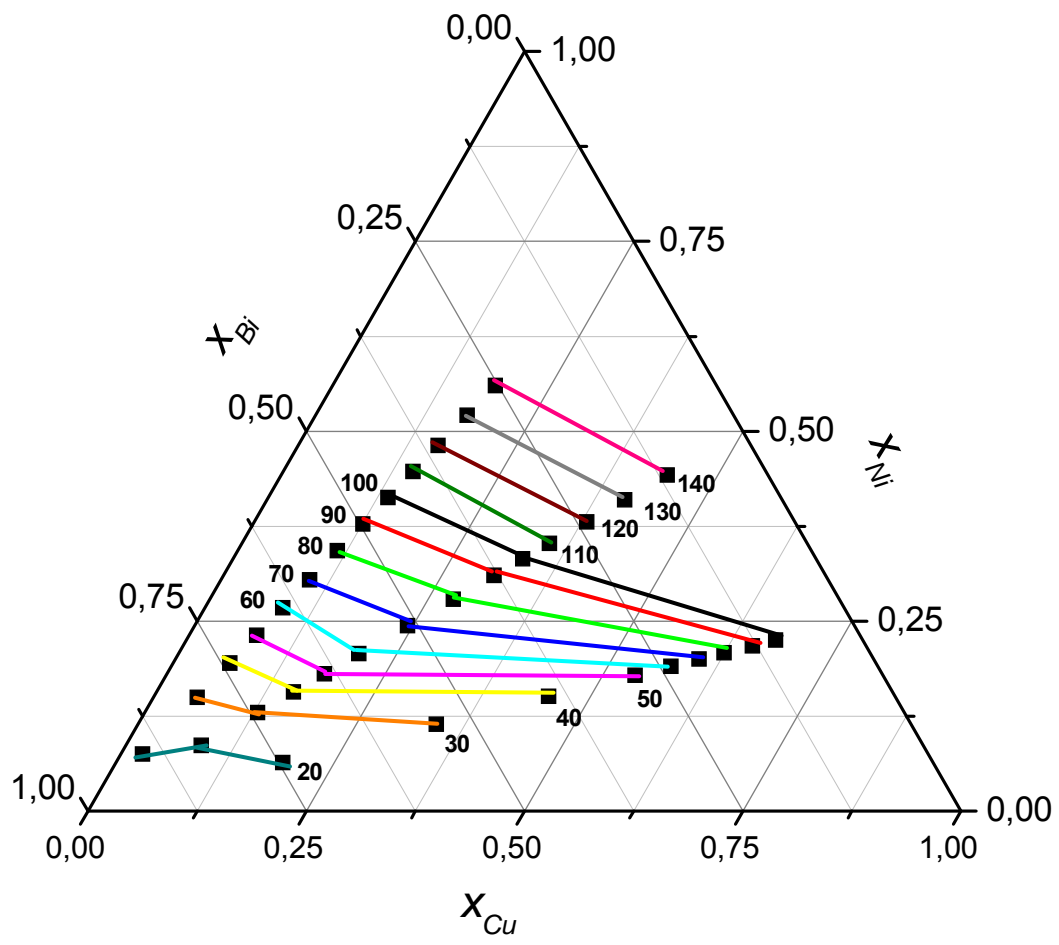

Fig. 6. The hardness iso-lines of the ternary Bi-Cu-Ni system (HV5).

When bismuth concentration increases, the hardness decreases rapidly for all samples in three investigated sections. Bismuth has the lowest hardness value compared to others in the $\mathrm{Bi}-\mathrm{Cu}-\mathrm{Ni}$ system, so the presence of Bi-based phases (BiNi, Bi3Ni and RHOMBO_A7) in the alloy structure will decrease the alloy hardness.

To complete the characterization of alloys in the ternary $\mathrm{Bi}-\mathrm{Cu}-\mathrm{Ni}$ system, the electrical conductivity measurements were done among three selected sections from the $\mathrm{Bi}$ corner, with $\mathrm{Cu}: \mathrm{Ni}$ molar ratio of $1: 1,3: 1$, and 1:3. The results are presented in Table 7 , while the changes of electrical conductivities with the Bi composition are shown in Fig. 7. The electrical conductivity decreases when bismuth amount increases. 
Table 7. The results of electrical conductivity measurements.

\begin{tabular}{|c|c|c|c|c|c|c|}
\hline \multicolumn{3}{|c|}{ Mole fraction of components } & \multicolumn{4}{|c|}{ Electrical conductivity $(\mathrm{MS} / \mathrm{m})$} \\
\hline \multirow[b]{2}{*}{$\mathrm{X}_{\mathrm{Bi}}$} & \multirow[b]{2}{*}{$\mathrm{XCu}_{\mathrm{Cu}}$} & \multirow[b]{2}{*}{$\mathrm{X}_{\mathrm{Ni}}$} & \multicolumn{3}{|c|}{ Values for different measurement } & \multirow{2}{*}{ Average value } \\
\hline & & & I series & II series & III series & \\
\hline 0.1 & 0.45 & 0.45 & 1.678 & 1.675 & 1.681 & 1.678 \\
\hline 0.2 & 0.4 & 0.4 & 1.534 & 1.533 & 1.524 & 1.530 \\
\hline 0.3 & 0.35 & 0.35 & 1.252 & 1.248 & 1.251 & 1.250 \\
\hline 0.4 & 0.3 & 0.3 & 1.173 & 1.172 & 1.173 & 1.173 \\
\hline 0.5 & 0.25 & 0.25 & 1.1150 & 1.1142 & 1.1148 & 1.1147 \\
\hline 0.6 & 0.2 & 0.2 & 0.9839 & 0.9847 & 0.9842 & 0.9843 \\
\hline 0.7 & 0.15 & 0.15 & 0.9658 & 0.9686 & 0.9675 & 0.9673 \\
\hline 0.8 & 0.1 & 0.1 & 0.9401 & 0.9388 & 0.9365 & 0.9385 \\
\hline 0.9 & 0.05 & 0.05 & 0.9071 & 0.9039 & 0.9025 & 0.9045 \\
\hline 0.1 & 0.675 & 0.225 & 2.826 & 2.824 & 2.830 & 2.8267 \\
\hline 0.2 & 0.6 & 0.2 & 1.907 & 1.904 & 1.905 & 1.9053 \\
\hline 0.3 & 0.525 & 0.175 & 1.5231 & 1.5196 & 1.5216 & 1.5214 \\
\hline 0.4 & 0.45 & 0.15 & 1.4126 & 1.4139 & 1.4150 & 1.4138 \\
\hline 0.5 & 0.375 & 0.125 & 1.2641 & 1.2616 & 1.2583 & 1.2613 \\
\hline 0.6 & 0.3 & 0.1 & 1.169 & 1.166 & 1.168 & 1.1677 \\
\hline 0.7 & 0.225 & 0.075 & 1.1301 & 1.1297 & 1.1289 & 1.1296 \\
\hline 0.8 & 0.15 & 0.05 & 1.005 & 1.006 & 1.006 & 1.006 \\
\hline 0.9 & 0.075 & 0.025 & 0.8969 & 0.8953 & 0.8952 & 0.8958 \\
\hline 0.5 & 0.125 & 0.375 & 1.0088 & 1.0095 & 1.0099 & 1.0094 \\
\hline 0.6 & 0.1 & 0.3 & 0.9585 & 0.9587 & 0.9589 & 0.9587 \\
\hline 0.7 & 0.075 & 0.225 & 0.9348 & 0.9346 & 0.9359 & 0.9351 \\
\hline 0.8 & 0.05 & 0.15 & 0.9211 & 0.9220 & 0.9221 & 0.9217 \\
\hline 0.9 & 0.025 & 0.075 & 0.8887 & 0.8896 & 0.8890 & 0.8891 \\
\hline
\end{tabular}



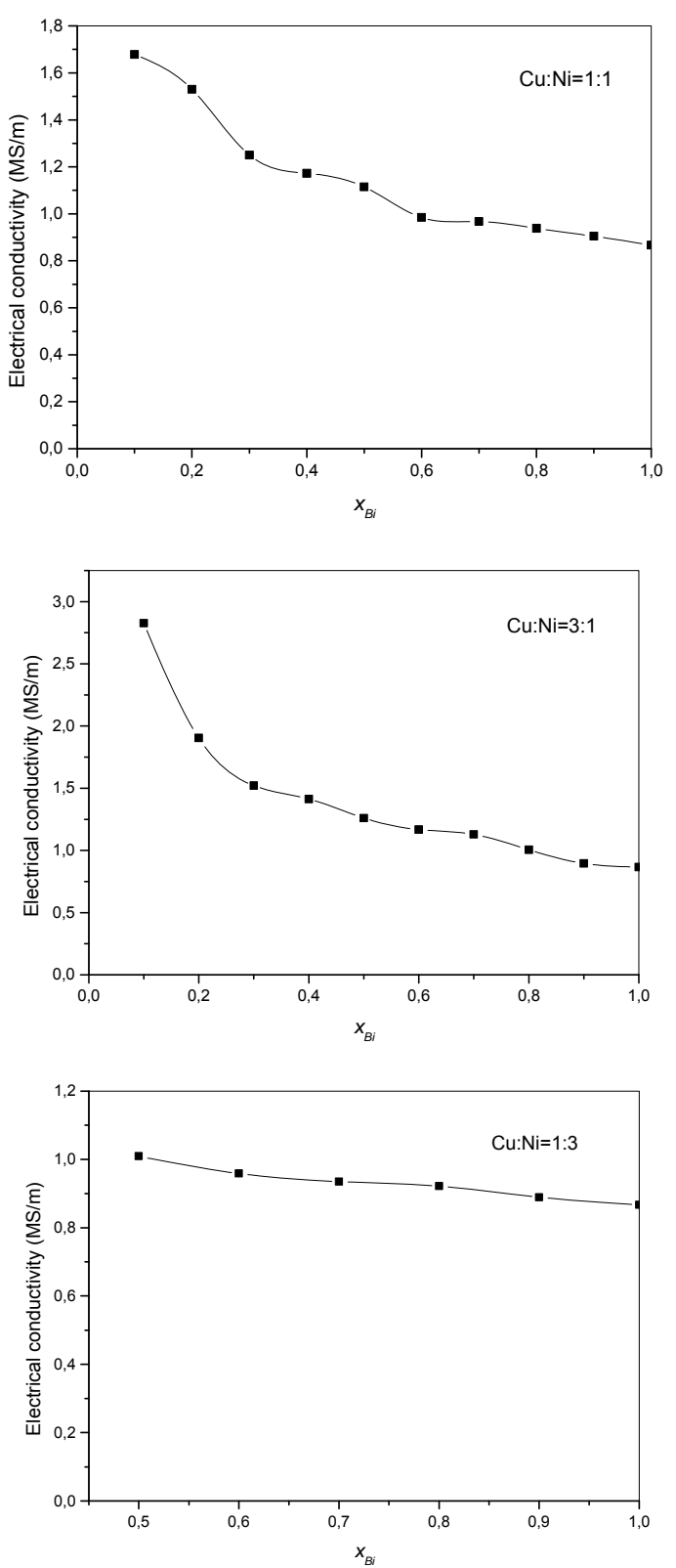

Fig. 7. The electrical conductivity change of the Bi composition with different Cu:Ni ratios. 
Based on these results, iso-lines of electrical conductivity in the ternary $\mathrm{Bi}-\mathrm{Cu}-\mathrm{Ni}$ system was constructed and shown in Fig.8.

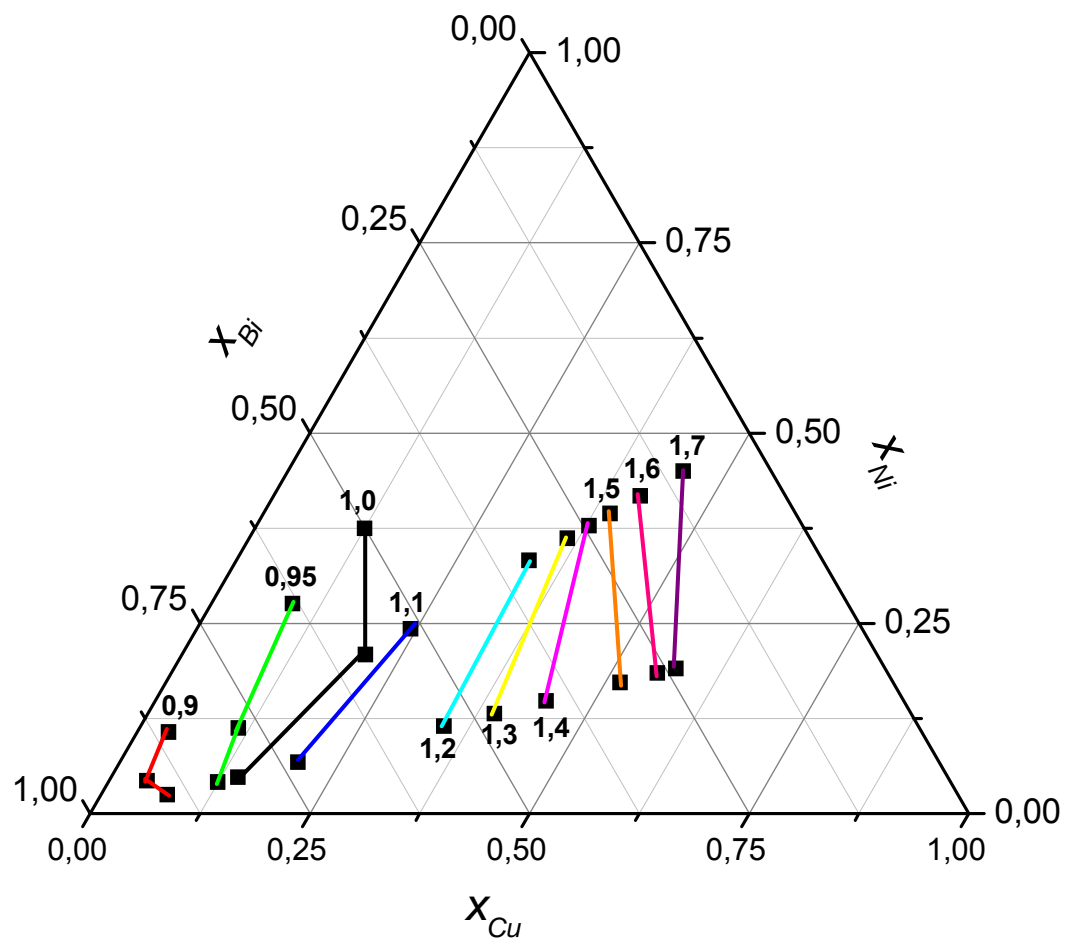

Fig. 8. The electrical conductivity iso-lines of the ternary Bi-Cu-Ni system (MS/m).

The electrical conductivity of pure $\mathrm{Bi}$ is about $0.867 \mathrm{MS} / \mathrm{m}[16,17]$; so, with decreasing amount of $\mathrm{Bi}$ in the alloy, the share of the Bi-based intermetallic compounds also decrease, increasing the electrical conductivity of the alloy.

\section{Conclusion}

In this study the results of the thermodynamic calculation, including integral molar Gibbs excess energy and calculated bismuth activities along the line of a constant $\mathrm{Cu}$ :Ni molar ratio of 1:1 at a temperature of $1273 \mathrm{~K}$ are presented. By DSC analysis, characteristic phase transition temperatures and liquidus temperatures were determined. All existing phases in this ternary system were confirmed by SEM-EDS analysis.

Hardness and electrical conductivity measurements show decreasing in their values with the increasing amount of $\mathrm{Bi}$ in the selected alloy, which is attributed to the presence of the Bi-based phases. Based on these results, iso-lines of hardness and electrical conductivity in the $\mathrm{Bi}-\mathrm{Cu}-\mathrm{Ni}$ ternary system were constructed.

Taking into account that the investigated $\mathrm{Bi}-\mathrm{Cu}-\mathrm{Ni}$ ternary alloy system has not been fully studied, the presented results represent a contribution to the better knowledge 
of thermodynamics, thermal, structural, mechanical and electrical properties of $\mathrm{Bi}-\mathrm{Cu}$ $\mathrm{Ni}$ alloys as new lead-free solder material for high temperature application.

\section{Acknowledgement}

This work presents the part of realization in the frame of projects $\mathrm{N}^{\circ} 172037$ and $\mathrm{N}^{\circ} 34023$, supported by the Ministry of Education, Science and Technological Development of the Republic of Serbia, and in the frame of European COST MP0602 Action "Advanced Solder Materials for High Temperature Application".

\section{References}

[1] Y. Li, C.P. Wong: Mater Sci Eng R, 51 (2006) 1-35.

[2] T. Laurila, V. Vuorinen, J.K. Kivilahti: Mater Sci Eng, 49 (2005)1-60.

[3] Y. Takaku, I. Ohnuma, R. Kainuma, Y. Yamada, Y. Yagi, Y. Nishibe, K. Ishida: J Electron Mater, 35 (2006) 1926-1932.

[4] J.N. Lalena, N.F. Dean, M.W. Weiser: J Electron Mater, 31 (2002) 1244-1249.

[5] M. Rettenmayr, P. Lambracht, B. Kempf, M. Graff: Adv Eng Mater, 7 (2005) 965969.

[6] A.T. Dinsdale, A. Kroupa, J. Vizdal, J. Vrestal, A. Watson, A. Zemanova, (2006) COST 531 Database for Lead-free Solders, Ver. 2.0, 2006, unpublished research, COST531 Homepage.

[7] V. Ćosović, D. Minić, M. Premović, D. Manasijević, A. Đorđević, D. Milisavljević, A. Marković: Metall Mater Eng, 23 (2017) 65-82.

[8] HISOLD - Advanced Solder Materials for High Temperature Application, http://www.ipm.cz/projects-hisold-advanced-solder-materials-for-hightemperature-application.html, Accessed 20 August 2017.

[9] F. Gao, X. Liu, Y. Takaku, I. Ohnuma, K. Ishida: J Mater Res, 24 (2009) 26443652

[10]B. Marković, D. Živković, J. Vřeštál, D. Manasijević, D. Minić, J. Stajić-Trošić, R. Todorović: Calphad, 34 (2010) 294-300.

[11] K.C. Chou: Calphad, 19 (1995) 315-325.

[12] K.C. Chou, W.C. Li, F. Li, M. He: Calphad, 20 (1996) 395-406.

[13] COST531 Thermodynamic Database, Vs.3.0 (2008).

[14]B. Marković, D. Živković, D. Manasijević, M. Sokić, D. Minić, N. Talijan, J. Stajić-Trošić: Arch Metall Mater, 59 (2014) 117-120.

[15] A. Dinsdale, A. Watson, A. Kroupa, J. Vrestal, A. Zemanova, J. Vizdal, COST Action 531 - Atlas of Lead free soldering: COST office, Brussels, 2008, pp. 124.

[16] http://www.chemicool.com, Accessed 25 August 2017.

[17]Electrical Conductivity of the elements, http://periodictable.com/Properties/A/ ElectricalConductivity.an.html, Accessed 25 August 2017.

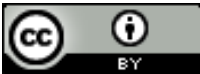

Creative Commons License

This work is licensed under a Creative Commons Attribution 4.0 International License. 